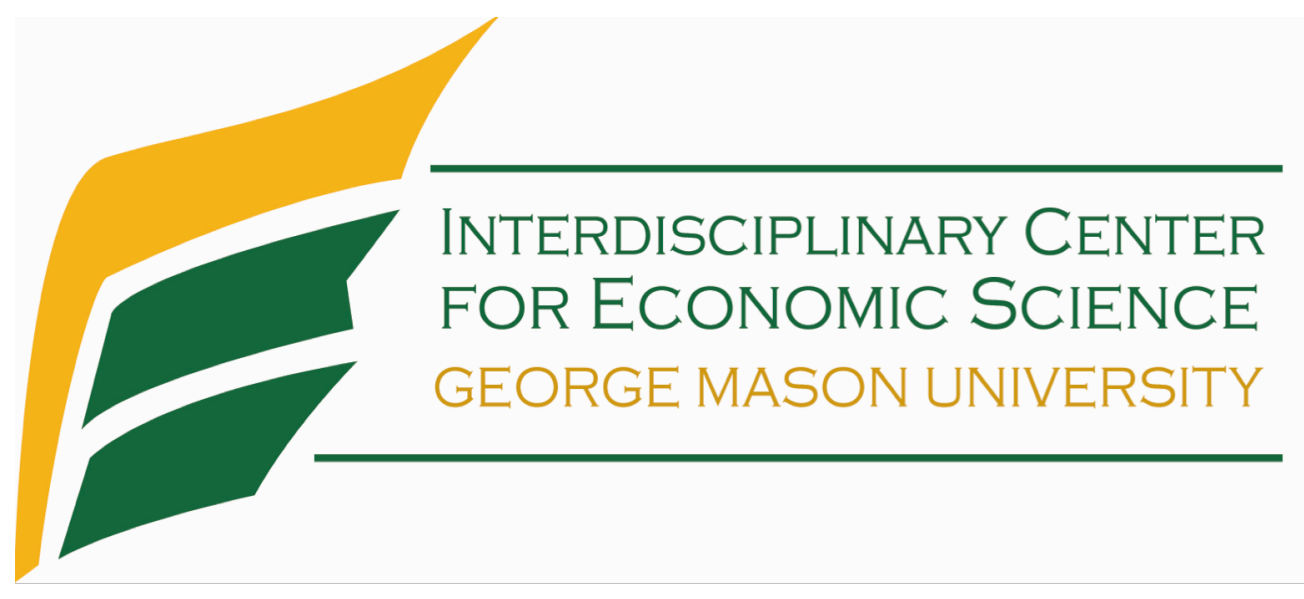

\title{
Good News, Bad News, and Social Image: The Market for Charitable Giving
}

Luigi Butera and Jeffrey Horn

March 2017

Discussion Paper

Interdisciplinary Center for Economic Science

4400 University Drive, MSN 1B2, Fairfax, VA 22030

Tel: +1-703-993-4719 Fax: +1-703-993-4851

ICES Website: $h$ ttp://ices.gmu.edu

ICES RePEc Archive Online at: http://edirc.repec.org/data/icgmuus.html 


\title{
Good News, Bad News, and Social Image: The Market for Charitable Giving *
}

\author{
Luigi Butera ${ }^{\dagger} \quad$ Jeffrey Horn ${ }^{\ddagger}$
}

This version: March 6, 2017

\begin{abstract}
We conduct a laboratory experiment with real donations to test how unexpected information about charities' qualities and its public visibility affect giving. A perceived increase in charities' qualities represents a decrease in the price of charitable output, and can generate both an income and substitution effect on nominal giving. On the one hand positive news about charities' qualities can increase giving, since donors realize that it is cheaper to generate charitable output. On the other hand positive news may crowd-out giving because donors may provide a higher or equal level of charitable output with lower nominal donations. Similarly, if information about quality has a social signaling value, then donors who give to acquire social recognition may perceive quality and quantity of giving as either complements or substitutes in generating social image returns. We find that when information about charities' qualities is privately received, giving is always increasing in the quality of the news, and bad news has little effect on giving. Differently, when information is public, we find that $34 \%$ of donors trade-off the quality and quantity of their gifts. We show that these donors are relatively more motivated by social recognition, and argue that image conscience donors strategically use positive information to reduce giving.
\end{abstract}

JEL-Classification: C91, D64

Keywords: Charitable Giving, Quality and Giving, Information, Laboratory Experiment.

${ }^{*}$ For helpful comments we thank Omar Al-Ubaydli, Jared Barton, Jon Behar, Marco Castillo, Rachel Croson, David Eil, Dan Houser, David Jimenez-Gomez, Chien-Yu Lai, Fatemeh Momeni, Ragan Petrie, Tali Sharot, and Marie Claire Villeval. We thank participants at ESA North-American meeting (2013), the Science of Philanthropy Initiative Conference Annual Conference (2013), and SEA meeting (2014). We gratefully acknowledge financial support from the GATE-LSE lab, CNRS and University of Lyon, and ICES, George Mason University. We thank Charity Navigator from providing access to the dataset.

${ }^{\dagger}$ The University of Chicago. 1160 E 58th St, office 225, Chicago, IL $60637 . \quad$ Email: lbutera@uchicago.edu - - Corresponding author.

${ }^{\ddagger}$ General Assembly Inc. Email: jrhorn424@gmail.com 


\section{Introduction}

The desire to improve others' well-being is an important motivation for charitable giving (Becker 1974), but people donate to charity also because the act of giving itself can generate private returns (Andreoni 1989). The nature of such returns varies: people may give to experience a warm-glow (Andreoni 1990), to be socially recognized (Harbaugh 1998a, 1998b; Bracha, Heffetz and Vesterlund 2009), to abide by social norms (Sugden 1984; Hollander 1990), or because of social pressure or guilt (Akerlof and Kranton 2000, Della Vigna et. al 2012). Common to all these forms of impure motives for giving is the fact that donors do not consider other people's donations as complete substitutes for their own contributions. As such, when more charitable output is produced because more resources flow in from other sources, private giving is not fully crowded-out (Andreoni 1988, 1989; Bergstrom et al. 1986).

Charitable output however can also be increased by improving the way in which it is produced: if charities become more effective and efficient in using resources, then recipients' well-being can increase. Previous research has studied donors' response to changes in the quantity of giving going to a charity, but little is known about how donors adjust their giving when they perceive that its quality has changed. Indeed the notion that people should strive to donate to efficient and effective charities has gained increasing popularity among donors, and information regarding charities' qualities has become widely and publicly available over the last decade. ${ }^{1}$ Yet, it is unclear how information that donors perceive as a signal of quality can affect the intensive margins of giving, such as giving from existing donors.

To answer this question we employ a laboratory experiment in which donors receive unexpected news about their charities' efficiency, a characteristics that donors seek and value when making giving decisions (Hope Consulting 2013; Gneezy et al. 2014; Meer 2017). ${ }^{2}$ The experiment is divided in two phases, revealed to participants sequentially. In the first phase participants select real charities and decide how much to donate. In a second phase, we elicit in an incentive compatible manner participants' beliefs about their charities' efficiency. We then reveal the actual information and allow donors to revise, if they want to, the giving decisions made in the first phase. We vary across treatments the public visibility of the amounts donated, a treatment condition revealed before phase 1 , and the visibility of the information about efficiency, a treatment condition revealed before

\footnotetext{
${ }^{1}$ The number of watchdogs organizations and crowdfunding platforms has grown over the years as well as the number of grant-making agencies focusing exclusively on evidence-based charitable programs. Nonprofit watchdog organizations monitor charities and provide assessments of their qualities. The type of information offered varies: some organizations, such as GiveWell, offer in-dept analyses of few selected charities. Others have developed synthetic indices used to rate all charities that make their tax returns or IRS Forms 990 available. Charity Navigator, Charity Watch and Give Star are a few examples of the latter category. Crowd-funding platforms allow individuals and non-profits to solicit donations from a large number of people. Some examples of crowdfunding platforms are GlobalGiving, Kiva.org, Razoo, DonorsChoose and Giveforward.

${ }^{2}$ See section 4.3 for a discussion about the limitations of measures of financial efficiency.
} 
phase 2. This information structure allows us isolate the pure effect of information on giving, and its effect on image conscience donors.

Intuitively, only donors who care about the well-being of the recipients, such as pure altruists, should modify their giving habits in response to news about their charities' qualities. Donors who instead give because they receive a private benefit from the act of donating itself should not respond to information related to charities' qualities. We argue that this may not be the case for image conscience donors if information can affect their social image. The problem is relevant, since information about charities' qualities has not just become more accessible but also more visible to (and easy to share with) peers, thanks to the growing presence of charities' initiatives or social networks. Such visibility may therefore affect donors who give to look good to others, who may realize that the output of their charitable investments can be scrutinized by peers and have an impact on their social image. Understanding how donors respond to information is important given the monetary and organizational costs charities face to produce and disseminate evidence of impact - for instance through randomized controlled trials - or to improve on standardized metrics used by watchdogs to rate charities. ${ }^{3}$ Few papers have studied how information about recipients' characteristics affects generosity (Fong 2007; Fong and Oberholzer- Gee 2011), and little is known about the effect information has when it is common knowledge. ${ }^{4}$

In which direction can information about charities' efficiency affect giving? An increase in the (perceived) quality of a charity can be considered as a reduction in the effective cost of giving, or the cost of producing one unit of charitable output (see Eckel and Grossman 1996). The effect of this price fall on donations depends on whether donors' utility is affected by the recipients' (perceived) well-being, which is determined by how nominal giving is perceived to convert into charitable output, or by the nominal giving itself. First, donors may only care about the well-being of the final recipient regardless of who produces it, as would be the case for pure altruist donors (Becker 1974). For these donors, a positive (perceived) change in the production technology of charitable output produces both an income and a substitution effect: on the one hand nominal giving may increase since charitable output has become cheaper to produce (substitution effect); on the other hand nominal giving may decrease since, all else equal, a smaller nominal donation can generate an equal or higher level of charitable output (income effect). ${ }^{5}$ Second, donors may derive a

\footnotetext{
${ }^{3}$ Standardized metrics such as measures of financial health or accountability are imperfect and highly debated, but they nevertheless heavily affect the ratings produced by most independent appraisers and watchdogs. Moreover, a recent survey conducted by Hope Consulting (2013) shows that administrative and financial efficiency constitutes the most demanded piece of information among donors who do research before giving.

${ }^{4}$ While this paper studies donors' response to exogenous exposure to information, an important question is whether donors voluntarily seek information about charities' qualities. For papers exploring donors' demand for information, see Fong and Oberholzer-Gee (2011), and Butera and Houser (2016). For an experimental study on how intermediaries affect giving by varying the implicit cost of giving see Chlaß et al. (2015).

${ }^{5}$ Giving may decrease also if donors target specific welfare outputs, such as helping a given number
} 
private benefit from giving and care only about the act of giving itself, as would be the case for warm-glow donors (Andreoni 1990), or donors who give in to social pressure or guilt (Akerlof and Kranton 2000; Andreoni et al. 2001; Della Vigna et. al 2012; Name-Correa and Yildrim 2016). In this case, an increase in charities' qualities would leave nominal giving unchanged. Finally, donors may give to appear pro-social and improve their social image (Harbaugh 1998a; 1998b; Bracha, Heffetz and Vesterlund 2009). Whether image motivated donors care about charitable output or nominal giving depends on which of the two affect social image. If nominal donations are the only signal visible to others, then changes in the perceived quality would have no effect on nominal giving. Differently, if both the quality and the quantity of donors' donations affect social image, then image conscience donors may behave as if they care about charitable output. On the one hand giving may increase when the perceived quality increases because the marginal image return from an extra unit of charitable output increases. On the other hand image motivated donors could take advantage of positive social signals about quality to reduce their nominal giving: they could give less but show that they are giving effectively.

We report two main results. First, we find that when positive information about charities' efficiency is received privately, $18 \%$ of donors modify their giving in response to this new information, displaying a behavior consistent with pure altruism, and such change is always increasing in the "quality" of news. Conversely, we find that donors tend to ignore negative news when the latter has no signaling value. Overall, we find that when information has no social signaling value, the majority of donors do not modify their giving in response to information, as would be expected from warm-glow givers. Second, we find that when the efficiency of donors' charities has a social signaling value, $34 \%$ of donors respond to this new information by reducing their giving when charities are better-than expected, and (marginally) increasing it when are worse. We show that this result is driven by individuals who are relatively more motivated by social image. Compared to the other participants, these donors give significantly more when the only social signal available is their monetary contribution (e.g. initial giving decisions), but decrease their contributions as soon as a new (costless) positive social signal can be conveyed to others, namely the efficiency of their charities. One explanation is that the subjective cost of looking pro-social decreases when positive public information is received, inducing thus image motivated donors to strategically use positive information to reduce their nominal giving.

\section{Background}

The economics literature has long addressed the question of why people donate money to private charities. Pure altruism fails to explain several empirical observations about

of children; this behavior is similar in spirit to what observed by Camerer et al. (1997) for taxi drivers pursuing daily income targets. 
charitable giving ${ }^{6}$, and different theories have been proposed and tested to explain private giving. In line with the intuition that individuals may derive a direct utility from giving (see i.e. Becker 1974), several motives have been identified as powerful motivations for giving, such as internalized norms (Arrow and Hahn 1971; North 1981), social approval (Hollander 1990), warm-glow (Andreoni 1990; Ribar and Wilhelm 2002; Harbaugh, Mayr and Burghart 2007), conditional cooperation (e.g. Fischbacher, Gachter, and Fehr, 2001), reciprocity (e.g. Sugden, 1984), and prestige (Harbaugh 1998a, 1998b; Bracha, Heffetz and Vesterlund 2009).

In particular, the empirical evidence of the importance of social image and prestige is vast. The possibility of direct and indirect social approvals generally increases individual contributions (Andreoni and Petrie 2004; Rege and Telle 2004). ${ }^{7}$ Not only donors give to actively increase their social reputation and therefore utility, but often they give in to social pressure, resulting in higher contributions but lower utility (Della Vigna, List, Malmendier 2012).

As individuals appreciate the positive image consequences of giving, their generosity depends also on the cost of giving - or nominal price of giving - (Andreoni and Miller 2003; Karlan and List 2007) and how others would perceive one's own generosity given its cost (Benabou and Tirole 2006; Ariely, Bracha and Meier 2009). Social influence and imitation as well play an important role (List and Lucking-Reiley, 2002; Shang and Croson 2009; Vesterlund 2003; Potters, Sefton and Vesterlund 2007; Bracha, Menietti and Vesterlund 2011), and social-signaling has been found to be a stronger motivation than self-signaling (Grossman 2010).

Although much is known about how warm glow and social image affect individual giving, less is known about these factors interact with the information available about charities' performances. $^{8}$ In this direction, Fong and Oberholzer-Gee (2011) use real individual recipients and costly information to show that a significant fraction of their subjects is willing to pay to gather information about the recipient and achieve a distribution of income that matches their preferences, and that they use this information to withhold resources to less preferred recipients. Overall however, with costly information not all donors are willing to invest resources to find preferred recipients. Brown et al. (2016) show in a laboratory experiment that third-party ratings do impact donors' choice of charities, but with no obvious preference for local charities. Karlan and Wood (2016) conduct a field experiment in which donors of a charity are sent fundraising letters including a paragraph reporting results from a randomized experiment. The authors find that on average the intervention

\footnotetext{
${ }^{6}$ For instance, large participation, incomplete government crowd out, average contributions non decreasing in the number of contributors. See Andreoni (1988).

${ }^{7}$ While social visibility often increases giving, recent studies have shown that individuals who are averse to both positive and negative reputation tend to conform toward the middle of others' contributions, resulting in a reduction in giving whenever others give less (Jones and Linardi 2014).

${ }^{8}$ For empirical evidence on the effects of identification versus information on the recipient see Small and Loewenstein (2003), Fong(2007), and Eckel, Grossman and Milano (2007).
} 
has no effect, but that it induces lower (higher) future donations among small (large) donors, suggesting that information about effectiveness may turn off the emotional trigger of giving among warm glow donors. Null (2011) finds that donors tend to allocate gifts among different charities even when this means reducing social surplus. Finally, in a recent paper Chlaß et al. (2015) explore how donors respond to the presence of intermediaries that can withhold resources, thus potentially reducing the charitable output produced a donation. The authors find that $41 \%$ of donors reduce giving when intermediaries are present, while $59 \%$ give as much or more.

\section{The effect of information on giving}

This section provides a simple model of how different donors may respond to perceived changes in the quality of their charities. We assume that (perceived) charities' characteristics and qualities can be summarized by a unique parameter $q \in[0 ; \bar{Q}]$. We also assume that the charitable output produced by any given charity, call it $\Omega$, is the product of the total nominal donations received from donor $i$ and all other donors $-i, G=G_{i}+G_{-i}$, and quality $q(\Omega=q \cdot G) .{ }^{9}$ Finally, we assume that donors have a fixed endowment of money $M$ that they allocate between private goods consumption $c$, and public goods production (charitable giving) $g$.

Pure altruist donors: Pure altruists give to charity to increase the welfare of the recipients or social wealth (Becker 1974). Pure altruists' utility is therefore affected by the total amount of charitable output produced $\Omega=q \cdot G$, regardless of who donates it, and private consumption $c$. The utility can then be characterized by $=U_{i}(c, q \cdot G)=U_{i}\left(c, q \cdot\left(g_{i}+G_{-i}\right)\right)$, where $G_{-i}$ represents giving from other donors. Without loss of generality, we assume that donors have additive utility over private consumption and giving $\left(U_{c g}^{\prime}=0\right)$, and that $U$ is strictly increasing and concave. The maximization problem then takes the following form:

$$
\begin{array}{r}
\max U_{i}(c, q \cdot G)=U_{i}\left(c, q \cdot\left(g_{i}+G_{-i}\right)\right) \\
\text { s.t. } M=c+g
\end{array}
$$

We assume that the equilibrium is an interior solution, $g_{i} *>0$. We further assume that donors are homogeneous, and we ignore the fact that other donors may respond to changes in $q$, that is, we assume $\frac{\partial G_{-i}}{\partial q}=0 .{ }^{10}$

\footnotetext{
${ }^{9}$ Note that $q$ can be interpreted either as perceived quality, or objective quality. Notice also that when $q<1$ a one dollar donation generates less than a dollar of charitable output.

${ }^{10}$ We make the latter assumption for the following reason: under Nash equilibrium conjectures, donors take other people's giving $G_{i}$ as exogenous (Andreoni 1989). This is true also in our context for any given level of $q$. When $q$ varies however, other donors' equilibrium giving $G *_{-i}$ clearly will vary with $q$, since other donors too will adjust their giving to changes in quality $q$. By assuming that donors are homogeneous, we are implicitly assuming then other donors' equilibrium response to changes in quality $\left(\frac{\partial G_{-i}}{\partial q}\right)$ will affect
} 
At the interior optimal level of giving $g *$, the marginal benefit of an extra unit of charitable output $\omega$ equals the marginal cost:

$$
q \cdot U_{g}^{\prime}\left(c, q \cdot\left(g_{i}+G_{-i}\right)\right)=U_{c}^{\prime}\left(c, q \cdot\left(g_{i}+G_{-i}\right)\right)
$$

Now suppose that the perceived quality $q$ increases by $1 \%$. Such increase shifts upwards the curve $q \cdot U_{g}^{\prime}\left(c, q \cdot\left(g_{i}+G_{-i}\right)\right)$ by $1 \%$ (the substitution effect). The $1 \%$ increase in $q$ also increases $q \cdot g$ (the charitable output) by $1 \%$ at any given level of $g$ (remember we assumed $\left.\frac{\partial G_{-i}}{\partial q}=0\right)$. The $1 \%$ increase of $q \cdot g$ however decreases $U_{g}^{\prime}\left(c, q \cdot\left(g_{i}+G_{-i}\right)\right)$, the marginal benefit of nominal giving, since $U$ is concave. The magnitude of this income effect depends on the curvature of the utility function, or how elastic the marginal benefit on nominal giving is to changes in nominal giving. This elasticity, call it $\lambda$, can be calculated as follows:

$$
\lambda=-\epsilon_{U_{g}^{\prime}(\cdot), g}=\frac{\partial u_{g}^{\prime}}{\partial g} \cdot \frac{g}{u_{g}^{\prime}}=-\frac{u_{g g}^{\prime \prime}}{u_{g}^{\prime}} \cdot g
$$

Overall thus, a $1 \%$ increase in perceived quality $q$ will shift $q \cdot U_{g}^{\prime}\left(c, q \cdot\left(g_{i}+G_{-i}\right)\right)$ by $(1-\lambda)$ percent. If $\lambda<1$, then the substitution effect will dominate the income effect and viceversa when $\lambda>1$. Figure 1, provides a visual representation of how $\lambda$ affects the new giving equilibrium. ${ }^{11}$ We derive the same results using a different analytic approach in appendix B.

Warm-glow donors: Warm-glow donors derive utility from the act of giving itself, rather than from the charitable output their giving generates. Their utility therefore only depends on their private consumption $c$ and nominal donation $g$, and therefore $U=U_{i}\left(c, g_{i}\right)$. It is immediate to see how a change in perceived quality $q$ has therefore no effect on giving. ${ }^{12}$

Social image donors: Donors who give to look good to others receive a private return from giving in the form of social image. If the only way to signal their pro-sociality is through nominal giving, then their preferences will look like those of warm-glow givers, meaning that a change in $q$ has no effect on giving. When both the quantity and the quality of their giving can be used for social signaling, then social image donors maximize over both quality and quantity. Call $\chi_{q}=\{0 ; 1\}$ a binary variable defining whether quality is visible or not to others, and $I$ as an increasing and concave image function; we can then characterize social image donors' function in its most general form as: $U_{i}=\chi_{q} I(c, q$.

the magnitude of the individual giving response to changes in quality, $\frac{\partial g_{i}}{\partial q}$, but not its sign. Since we are interested in the direction of the effect of $q$ on $g_{i}$, but not in it's magnitude, we ignore the magnitude effect of other donors' adjustments to $q$.

${ }^{11}$ We adapt the representation and analysis approach of Chetty (2006) to a giving environment.

${ }^{12}$ Karlan and Wood (2016) point out that information about charities' qualities may negatively affect giving if receiving such information interferes with the emotional component of giving (Small, Loewenstein, and Slovic 2007). Both formulations of warm-glow giving however do not predict an increase in giving, which is important for the interpretation of our data. 
$\left.\left(g_{i}+G_{-i}\right)\right)+\left(1-\chi_{q}\right) \cdot I_{i}\left(c, g_{i}\right){ }^{13}$ When $\chi_{q}=1$, the effect of the information on giving is similar to the pure altruism case: on the one hand an increase in $q$ increases the marginal image return from an extra unit of charitable output; on the other, a higher or equal level of charitable output, and therefore of social image, can be achieved with a lower nominal donation. ${ }^{14}$

\footnotetext{
${ }^{13}$ If both $g$ and $q$ are private information, then a social image donor never gives.

${ }^{14}$ Notice that the latter specification of the social image utility function implicitly assumes that other people always observe the quality $q$ at any point in time, meaning that they always observe any change in quality $\Delta q$. In turns, this means that an image motivated donor knows that other people observe how he responds to changes in quality. This is the main source of the substitution effect for image motivated donors: because there is a increase in quality, and because the increase itself is observed by others, then an extra unit of charitable output generates a larger image benefit. In our experiment other participants only observe one level of efficiency, which the donor may perceive as a positive or negative piece of information based on his beliefs. When there is a one-time disclosure of positive information, either voluntary or involuntary, then the presence of such positive information directly reduces the cost of increasing social image through nominal giving.
} 
Figure 1: The effect of information on giving from pure altruist donors or social image donors

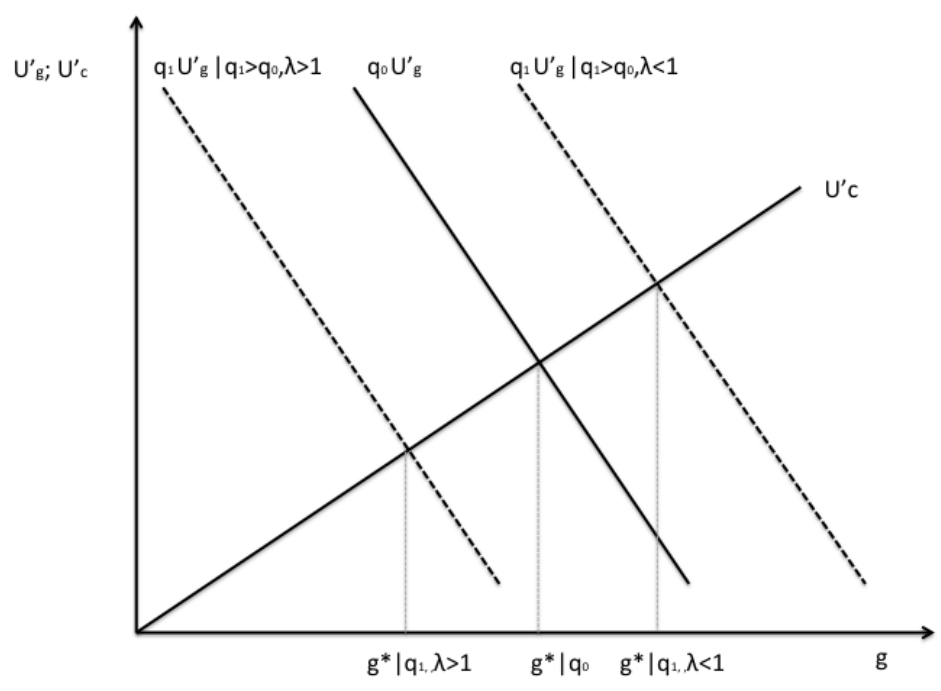

Note: The figure shows the giving decision of a pure altruist donor (the same logic applies to a social image donor) at two different quality levels of a charity ( $q_{0}$ and $q_{1}$, with $q_{1}>q_{0}$ ) assuming that utility is quasi-linear. The upward sloping curve $u_{c}^{\prime}$ represents the marginal cost (or opportunity cost) of an extra unit of nominal giving. The downward sloping solid curve represents the marginal benefit of one extra unit of charitable output, $q \cdot U_{g}^{\prime}$. The optimal level of donations $g *$ is determined by the intersection of these curves. The two dashed curves represent the shift of $q \cdot U_{g}^{\prime}$ in response to a change in quality under two different cases: the upper curve represents a shift corresponding to the case in which the substitution effect dominates the income effect. In this case an increase in quality increases giving. The lower dashed curve depicts the new curve when the income effect dominates the substitution effect. In this case an increase in quality decreases giving.

\section{Experiment design}

\subsection{Overview and Treatments}

Subjects participate in a simple individual decision making experiment. The experiment consists in two phases, with the second phase disclosed to subjects only at the end of the first phase. In the first phase of all treatments, subjects choose three charities from a large list of real charities. Subjects choose how to split their endowment between themselves and each of the three charities, knowing that only one split (and thus one charity) is randomly selected for final implementation. In the second phase subjects receive new information about their charities' efficiency and are allowed to modify their initial decisions. One of 
three decisions from the second and last phase is randomly selected for payments. Subjects and the selected charity are paid accordingly.

We design three treatments for this experiment, each with two aforementioned phases. Our three treatments differed in whether the final donation implemented is publicly revealed at the end of the experiment, and whether the information each subject receive is publicly revealed at the end of the experiment. In all treatments the name of the randomly chosen charity is never revealed to other participants nor to the experimenter. The name and personal information of all subjects is also never revealed. In our baseline treatment T0 all decisions and information are private. In treatment 1 (T1), subjects are required to stand up at the end of the experiment and announce how much they donated to the randomly chosen charity. In treatment 2 (T2), subjects are required to stand up at the end of the experiment and announce both the amount donated and the information received in the second phase about that final charity. Subjects in T1 and T2 are explicitly told that the name of the charity may never be revealed.

The timing of information disclosure is a critical feature of our design. At the beginning of phase 1, participants learn whether their donation decision will be private or publicly revealed. At the beginning of phase 2, participants learn whether the efficiency of the randomly chosen charity will be private or publicly revealed. Note that phase 1 decisions are fully comparable across treatments $\mathrm{T} 1$ and $\mathrm{T} 2$, since in both treatments the information set is the same: subjects only know that the donation to the randomly selected charity will be publicly revealed, but are unaware of the second phase, and therefore that further information will be received.

\subsection{Detailed procedure}

Subjects are endowed with 25 experimental dollars (henceforth $\mathrm{E} \$$, equivalent to US\$17), and are presented with a web-based search idatabase of approximately 5,400 charitable organizations rated by the charity watchdog Charity Navigator $(\mathrm{CN}) .{ }^{15}$ Subjects are asked to select three charities from the database and to rate their familiarity with, and attitude toward each charity. After completing a comprehension quiz, subjects decide how to split their initial endowment of $\mathrm{E} \$ 25$ between themselves and each charity separately. Any integer donation between $\mathrm{E} \$ 0$ and $\mathrm{E} \$ 25$ is allowed. Participants know that the three decisions are independent, meaning that at the end of the experiment only one decision is randomly selected for implementation, and that subjects are paid according to the split of $\mathrm{E} \$ 25$ chosen for that randomly-selected charity. Before the beginning of phase 1, subjects in treatments $\mathrm{T} 1$ and $\mathrm{T} 2$ are informed that the donation amount they allocate to the randomly-implemented charity will be publicly revealed at the end of the experiment.

\footnotetext{
${ }^{15}$ We chose to give a large list of charities to increase the chances that participants could select a charity they actually care about, increasing thus the external validity of the experiment. The interface works like traditional web search engines, allowing subjects to narrow their search with each keystroke, a so-called "fuzzy matching". This interface made it easy for subjects to search and browse for charities.
} 
Subjects are given the possibility to increase the probability that one of the three charities is implemented by indicating one charity as favorite. Subjects know that if no favorite is indicated, each decision stands a one in three chance of being implemented ( $\mathrm{Pr} .=33.3 \%)$. However, conditional on a favorite being chosen, that favorite charity stands an increased chance of being implemented of two in three (Pr. $=66.6 \%)$

At the end of Phase 1, subjects are informed that a second and last phase begins, and that they will receive additional information about the charities they chose. After information is received, they will be able modify, if they want, their decisions from phase 1 , including the choice of a favorite charity. We explain that this second set of decisions is the only one that will be considered for final payments. ${ }^{16}$ Subjects are then provided with explanations and examples about a single, homogenized measure used by Charity Navigator to rate charities called "program expenses". ${ }^{17}$ Program expenses is the ratio of dollars spent providing services in pursuit of the charity's stated mission. The residual below unity can be thought of as the percentage of a charity's budget spent on fundraising and administrative expenses. After a quick comprehension quiz about Charity Navigator's mission and the interpretation of the efficiency measure, subjects are asked to guess each charity's actual program expenses ratio, as well as how confident they are in their guess by asking to provide the likelihood that the true ratio falls within each of five quintiles. Subjects are informed that after this guessing phase,they will be told the real value for each charity, and if their guess is within $+/-5 \%$ from the true value, they will receive additional $\mathrm{E} \$ 6$ at the end of the experiment. We remind subjects in T1 and T2 that the donation amount they allocated to the final (phase 2) randomly-implemented charity will be publicly revealed at the end of the experiment, and subjects in T2 are informed that the program expenses rating of the randomly-selected charity will be revealed as well. Subjects in T0 are instead reminded that all their decisions and information will be kept private. At the end of the experiment, in T0 subjects are called one by one and paid by a third person not related to the experiment. In T1, subjects are asked to stand up and announce in front of other participants how much they donated to their final charity, and then paid in private. In T2, subjects are asked to stand up and announce in front of other participants how much they donated to their final charity, and announce its efficiency rating. Participants are then paid in private. Once again, in all treatments the names of the charities are not revealed either to the experimenter or to other participants.

We recruited 99 subjects from George Mason University. The mean age was 22.25, with about $54 \%$ of men and $46 \%$ of women; $70 \%$ of subjects took at least one course in Economics (with $57 \%$ having taken more than 2 courses). ${ }^{18}$ Data were collected using pencil-and-

\footnotetext{
${ }^{16}$ Note that there is no deception involved in the experiment, since all decisions made in phase 1 are still part of the action set of participants in phase 2. Moreover, decisions made in phase 1 are never revealed to anyone, meaning that others never learn whether a subject's final decision is different from the decision made in phase 1 .

${ }^{17}$ Charity Navigator, section "How Do We Rate Charities' Financial Health?"

${ }^{18} 67.4 \%$ of subjects declared to have donated money at least once in the last year (any sum to anyone),
} 
paper, but subjects used a computerized search interface for part of the experiment.

\subsection{Discussion about measures of financial efficiency}

Measures of financial health and efficiency represent an imperfect way to assess how well charities serve their mission, and have been widely criticized by many economists and practitioners. Administrative and fundraising costs are fixed costs that are necessary for any charity to capture scale economies (Perroni et al. 2014), and there is evidence that an excessive focus on overhead costs induces charities to under-invest in critical assets, such as skilled personnel (Meer 2017). Yet, donors appear to highly value such information and to consider it as a proxy for charities' quality. A survey from Hope Consulting (2013) finds that overhead costs constitute the most demanded piece of information among donors who do research before giving, and Meer (2017) reports a recent survey from Grey Matter Research finding that nearly two thirds of Americans believe that charities spend too much on overhead costs. Gneezy et al. (2014) show in a field experiment that fundraising outcomes can be dramatically improved by merely framing a large seed donation as a contribution covering all overheads. Since the focus of our paper is to assess how a change in attributes that are perceived by donors as proxies for charities' qualities affect giving, we chose to focus on this single aspect of non-profits' activities. While an increase in charities' efficiency represents a perceived increase in quality, we do not claim that higher financial efficiency necessarily equates to higher charitable output.

\section{Results}

We organize our results as follows: in section 5.1 we present general results on (i) overall donations; (ii) real efficiency levels and individual guesses about efficiency; and (iii) decisions about favorite charities. In section 5.2 we combine individual guesses and real efficiencies to examine how the quality of information (bad/good news) about charities' efficiency affects donation levels and choices of the favorite charity across treatments. For our analysis we will assume that subjects receive good news when their guess about efficiency is lower than the actual value, and receive bad news in the opposite case.

\subsection{General results}

Table 1 presents descriptive statistics of average giving in each phase, percentage of subjects indicating a favorite charity, guesses and real values of charities' efficiency.

$69.8 \%$ to have volunteered, and $12 \%$ to have tithed. 
Table 1: Summary Statistics

\begin{tabular}{lccc}
\hline Summary Statistics & T0 $(\mathbf{n}=\mathbf{8 1})$ & T1 $(\mathbf{n}=\mathbf{8 4})$ & T2 (n=132) \\
\hline Donation Phase 1 & 8.86 & 10.30 & 8.84 \\
& $(8.18)$ & $(7.88)$ & $(7.92)$ \\
Donation Phase 2 & 9.45 & 10.49 & 8.86 \\
& $(8.48)$ & $(8.24)$ & $(8.23)$ \\
Choose Favorite in Phase 1 & $66 \%$ & $78 \%$ & $70 \%$ \\
& $(0.47)$ & $(0.41)$ & $(0.46)$ \\
Choose Favorite in Phase 2 & $62 \%$ & $85 \%$ & $77 \%$ \\
Efficiency Guess & $(0.48)$ & $(0.35)$ & $(0.42)$ \\
& 68.93 & 74.15 & 68.98 \\
Real Efficiency & $(18.07)$ & $(11.39)$ & $(18.13)$ \\
& 79.50 & 82.34 & 80.04 \\
& $(15.14)$ & $(8.41)$ & $(13.63)$ \\
\hline
\end{tabular}

\subsubsection{Donations}

Overall, participants donate a significant part of their endowment of $\mathrm{E} \$ 25$ to the charities they choose. With only $16.8 \%$ of subjects donating zero in phase 1 , and $17 \%$ donating zero in phase 2, participants give on average $\mathrm{E} \$ 9.25$ in phase 1 , and $\mathrm{E} \$ 9.48$ in phase 2. This leaves to subjects average final earnings of US $\$ 17$ (including show up fee). A two-sided Jonckheere-Terpstra test shows that donations in phase 1 are not significantly different across treatments $(\mathrm{p}=0.724)$; similarly, donations in phase 2 are overall similar across treatments $(\mathrm{p}=0.392) .{ }^{19}$ Finally, the average difference of donations between phases is not different across treatments $(\mathrm{p}=0.282) .{ }^{20}$

\subsubsection{Efficiency and guesses about efficiency}

Real efficiency values encountered both within and between treatments are fully comparable. The total average of real efficiency is $80.5 \%$ (s.d. 12.85) (all three treatments), and between-treatment averages are not significantly different $(\mathrm{p}=0.792)$. This means that across treatments subjects selected charities very similar in terms of efficiency. Further, we do not find evidence that some subjects systematically received significantly skewed draws

\footnotetext{
${ }^{19}$ When we look at phase 1 donations in $\mathrm{T} 1$ and T2, we find that they are statistically indistinguishable from T0 $(\mathrm{p}=0.565)$. This is surprising since numerous papers have shown that public visibility of giving generally increases donors' contributions. One explanation for this difference is that in most of those papers individuals face only one decision while in our experiment each participant takes three simultaneous decisions.

${ }^{20}$ Unless mentioned otherwise, all p-values from pairwise comparisons come from two-sided WilcoxonMann-Whitney tests or Wilcoxon matched-pairs signed-rank tests. For trend comparisons of three treatments, all reported p-values come from two-sided Jonckheere-Terpstra tests.
} 
in terms of charities' efficiency, both within and across each treatment. We draw the same conclusion for participants' guesses across and within treatments. To compare guesses across treatments one additional check is needed: in treatment T2, unlike the other two treatments, participants guess the efficiency knowing that its true value will be revealed to others. The way in which people form beliefs thus may be biased by this information. By comparing average guesses across treatments however, we cannot reject the hypothesis that subjects in T2 form their guesses in the same way participants in T0 and T1 do ( $p=0.459)$. Finally, average guessing errors are not significantly different across treatments $(p=0.839)$. Taken together, these results show that across treatments, participants received the same proportion of good and bad news (difference between guesses and real values). Therefore our results are not a consequence of systematic differences of the quality of information and/or individual guesses across treatments. Table 5.1.2 shows the proportion of good and bad news received in each treatment.

Table 2: Proportion of good/bad news received by treatment

\begin{tabular}{cccc}
\hline & Good News & Bad News & Total \\
\hline & & & \\
T0 & $60(74.07 \%)$ & $21(25.93 \%)$ & $81(100 \%)$ \\
T1 & $64(76.19 \%)$ & $20(23.81 \%)$ & $84(100 \%)$ \\
T2 & $102(77.27 \%)$ & $30(22.73 \%)$ & $132(100 \%)$
\end{tabular}

Note: proportion of good news (guess $<$ real value) and bad news (guess $>$ real value) by treatment.

Guesses and information are not different across treatments, but systematic differences across treatments may still exist with respect to the type of charities selected. If this is the case, unobserved characteristics of specific charitable causes may confound our analysis. Table 3 reports, for each treatment, the distribution of subjects' chosen charities by sector of activity. Using a Jonckheere-Terpstra test, we cannot reject the hypothesis that the distribution of sectors is the same across treatments $(\mathrm{p}=0.476)$. The same conclusion can be drawn if we break down sectors into sub-sectors of activity $(\mathrm{p}=0.577) .{ }^{21}$

\footnotetext{
${ }^{21}$ These categories are the ones used by Charity Navigator. These categories are never presented to participants at any point during the experiment. See table 7 of Appendix A for a list of categories and the number of charities chosen in each category by treatment. For the full list of charities selected by participants see Table 7 Appendix A
} 
Table 3: Distribution of selected charities across sectors, by treatment

\begin{tabular}{lccc}
\hline Treatments & T0 & T1 & T2 \\
& n. $(\%)$ & n. $(\%)$ & n. $(\%)$ \\
\hline Animals & $7(8.7 \%)$ & $10(11.9 \%)$ & $11(8.3 \%)$ \\
Arts, Culture, Humanities & $7(8.7 \%)$ & $4(4.7 \%)$ & $5(3.7 \%)$ \\
Education & $6(7.4 \%)$ & $5(5.9 \%)$ & $10(7.5 \%)$ \\
Environment & $5(6.1 \%)$ & $3(3.5 \%)$ & $3(2.2 \%)$ \\
Health & $19(23.4 \%)$ & $16(19 \%)$ & $34(25.7 \%)$ \\
Human Services & $12(14.8 \%)$ & $15(17.8 \%)$ & $26(19.6 \%)$ \\
International & $13(16 \%)$ & $15(17.8 \%)$ & $22(16.6 \%)$ \\
Public Benefit & $9(11.2 \%)$ & $10(11.9 \%)$ & $18(13.6 \%)$ \\
Religion & $3(3.7 \%)$ & $6(7.1 \%)$ & $3(2.3 \%)$ \\
\hline Total & $81(100 \%)$ & $84(100 \%)$ & $132(100 \%)$ \\
\hline
\end{tabular}

\subsubsection{Indicating a favorite}

We finally turn to decisions about indicating a favorite charity. We find that overall most participants choose to indicate a favorite in both phase 1 ( $71 \%$ of subjects) and phase 2 $(75.7 \%)$. The percentage of subjects choosing a favorite in phase 1 is not different across all three treatments $(\mathrm{p}=0.921)$, as well as when we compare treatment T0 with $\mathrm{T} 1$ and T2 pooled together $(\mathrm{p}=0.672)$. The latter result is important because it rules out that the visibility of donation amounts (known from phase 1) alters individual preferences for indicating or not a favorite charity. For choices in phase 2, we find that more participants choose to indicate a favorite charity in phase 2 when we move from T0 to T1 to T2 (Jonckheere Terpstra test, $\mathrm{p}=0.070$ ). Moving from T0 to T1 to T2, subjects also switch favorite from phase 1 to phase 2 more often $(\mathrm{p}=0.001)$. When participants choose to select a favorite in phase 2 and/or switch favorite, it is always a switch in favor of a more efficient charity (for treatments $\mathrm{T} 0, \mathrm{~T} 1, \mathrm{~T} 2, \mathrm{p}=0.142, \mathrm{p}=0.043, \mathrm{p}=0.026$ respectively). ${ }^{22}$

\subsection{The effect of good and bad news on donations}

The previous sections show that participants donate a significant portion of their endowment, that they face comparable efficiency levels across treatments, and that their guesses are comparable across treatments. These general results allow us to analyze in depth how the subjective quality of news, the objective value of efficiency, and its social visibility affect giving. As a reminder, we define "news" as the difference between an individual guess about the efficiency of a charity and its real value. We assume that donors whose guess is lower than the real value receive good news, and donors whose guess is higher than the

\footnotetext{
${ }^{22}$ We obtain the same result comparing the real efficiency of all charities with the real efficiency of charities selected as favorite in round 2 .
} 
real value receive bad news. Figure 2 provides a scatter plot of the relationship between changes in donation amounts between phases (donation made in phase 2 minus donation made in phase 1) and the type (and intensity) of news received in phase 2 (difference between real values of efficiency and subjects' guesses).

Figure 2: Changes in donations across phases by type of news

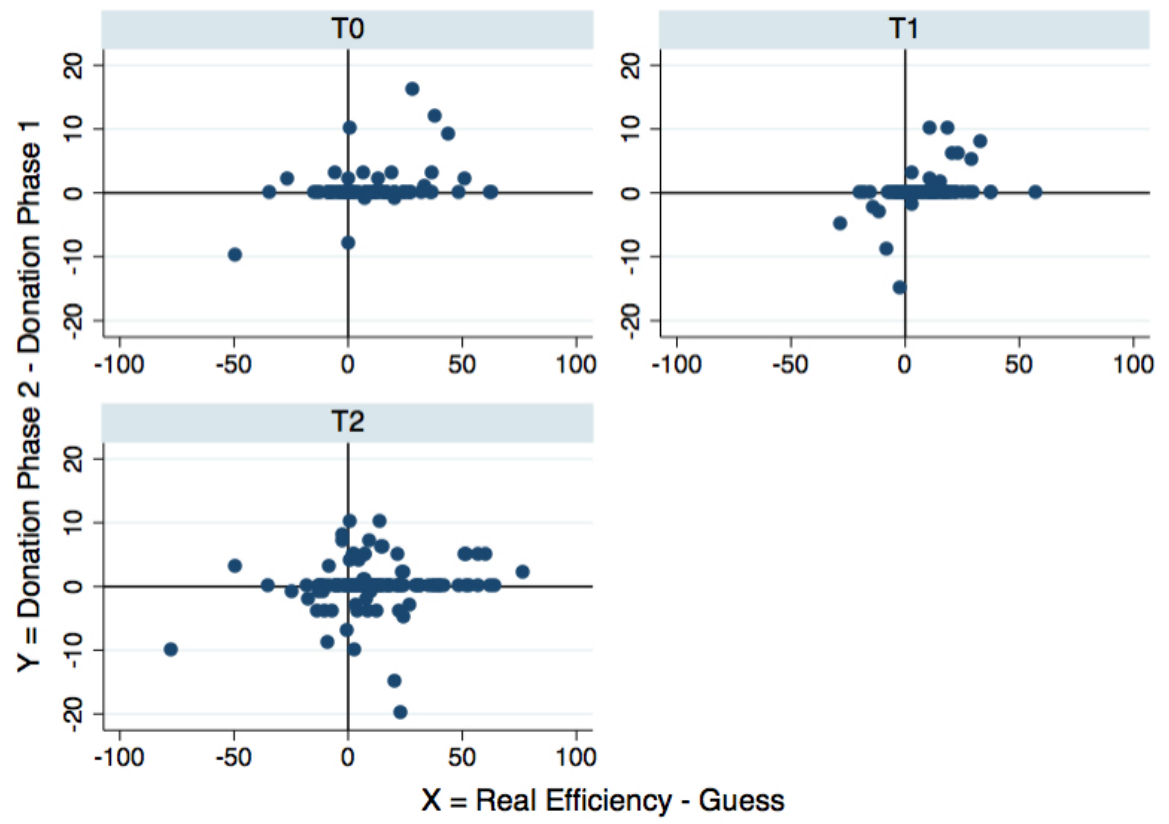

It can be noticed that the public visibility of efficiency has a big effect on donors' behavior. Treatments $\mathrm{T} 0$ and $\mathrm{T} 1$, in which efficiency is always private information, share the same pattern of response to good news: in both treatments, a response to good news is always in the direction of an increase in giving. Differently, in T2 a large fraction of subjects reduce their donations when good news is received. The only difference between T2 and the other two treatments is the visibility of the final charity's efficiency, therefore the emergence of this new behavioral pattern can only be attributed to the social image value information has in T2. As a preliminary test for the effect of social image on giving, we estimate the following linear model with panel-level random effects:

$$
G 2_{i j}=\mathbf{x}_{i j} \beta+\mathbf{z}_{i j} \gamma+\nu_{i}+\epsilon_{i j}
$$

where our dependent variable $G 2_{i j}$ represents the transfer made by subject $i$ to charity 
$j$ in phase 2 of the experiment as a function of (i) a vector of charities' characteristics, individual giving decisions, and individual giving decisions interacted with their social visibility, $\mathbf{x}_{i j}$, and (ii) a vector of demographic controls $\mathbf{z}_{i j}$. We assume random effects $\nu_{i}$ are i.i.d., $N\left(0, \sigma_{\nu}^{2}\right)$, and $\epsilon_{i j}$ are i.i.d. $N\left(0, \sigma_{\epsilon}^{2}\right)$ independently of $\nu_{i}$. Our main variables of interest, $\mathbf{x}_{i j}$, include: (i) the donation made in phase 1 , and its interaction with our public treatments; (ii) the effect of news, real efficiency, and efficiency's public visibility; (iii) the choice of a favorite charity in phase 2 , and its interaction with public treatments, and (iv) the general effect of our public treatments on final decisions ( $\mathrm{T} 0$ vs $\mathrm{T} 1 \cup \mathrm{T} 2$ ). To assess the effect of these variables on subjects' final donations, we control for a set of individual characteristics and survey questions, $\mathbf{z}_{i j}$, including age, GPA, number of Economics classes attended, personal and family opinions on charity $j$, general pro-social habits, and general attitudes towards risk.

Table 4 reports estimates from a random-effects Tobit regression. ${ }^{23}$ Results point to three important observations: first, donations made in phase 2 are significantly higher in treatments where some, or all relevant information is revealed to others (Public Treatments, $\mathrm{p}=0.077$ ). Second, all else constant, donors increase their giving in response to increases in the relative efficiency of their charities (News, $p=0.000$; Efficiency, $p=0.387$ ). Third, controlling for news effect, donors reduce their giving when information about efficiency is revealed to others $(\mathrm{p}=0.029)$. Finally, the (average) news received for the two other decisions has no significant effect on giving $(\mathrm{p}=0.432)$. In addition, favorite charities receive significantly larger donations only in our public treatments $(p=0.327$ for the whole sample, and $\mathrm{p}=0.032$ for $\mathrm{T} 1$ and $\mathrm{T} 2$ ). Finally, only few personal characteristics have a significant, positive effect on giving in the last phase (reported as controls in table 4, see table note for full list). These include the perceived importance of the charity $(\mathrm{p}=0.051)$, the reported GPA $(\mathrm{p}=0.009)$, having tithed in the last year $(\mathrm{p}=0.007)$, and (only marginally) the self-reported willingness to take risks in life $(\mathrm{p}=0.088)$. Having taken economics courses negatively affects giving $(\mathrm{p}=0.041)$.

\footnotetext{
${ }^{23}$ As $29 \%$ of our observations are potentially censored, we opted for a Tobit model. In addition, we used the same specification to run two fixed and random-effects GLS models (not reported here), whose parameter estimates are not statistically different one from each other (Hausman test, $\mathrm{p}=0.267$ ).
} 
Table 4: The effect of news and efficiency's visibility on giving

\begin{tabular}{|c|c|}
\hline Dependent Variable & Donation 2 \\
\hline Model & RE Tobit \\
\hline Public Treatments $(0=\mathrm{T} 0 ; 1=\mathrm{T} 1+\mathrm{T} 2)$ & $\begin{array}{l}5.753^{*} \\
(3.258)\end{array}$ \\
\hline Donation 1 & $\begin{array}{c}1.166^{* * *} \\
(0.070)\end{array}$ \\
\hline Donation 1 x Public Treatments & $\begin{array}{l}-0.068 \\
(0.071)\end{array}$ \\
\hline News (Real Eff. - Guess) & $\begin{array}{c}0.067^{* * *} \\
(0.017)\end{array}$ \\
\hline Real Efficiency & $\begin{array}{c}0.028 \\
(0.033)\end{array}$ \\
\hline Real Efficiency x T2 & $\begin{array}{c}-0.087^{* *} \\
(0.040)\end{array}$ \\
\hline News Other 2 Charities & $\begin{array}{l}-0.139 \\
(0.177)\end{array}$ \\
\hline Favorite Phase $2(0=\mathrm{No} ; 1=\mathrm{Yes})$ & $\begin{array}{c}0.704 \\
(0.719)\end{array}$ \\
\hline Favorite Phase $2 \times$ Public Treatments & $\begin{array}{l}2.213^{* *} \\
(1.033)\end{array}$ \\
\hline Controls & YES \\
\hline Constant & $\begin{array}{l}-4.580 \\
(2.799)\end{array}$ \\
\hline Observations & 297 \\
\hline Number of subjects & 99 \\
\hline
\end{tabular}

Note: the table reports estimates from a random-effects Tobit regression. Controls include the following demographic characteristics: age; current GPA; whether the subject has ever taken an Economics course and if so, how many; whether the subject has donated, tithed, or volunteered in the previous year $(0=\mathrm{No} ; 1=\mathrm{Yes})$; whether the subject's family has donated to the charity in the previous year $(0=\mathrm{No} ; 1=\mathrm{Yes})$. Controls also includes the following self-reported information: importance and knowledge of the charity for the donor and for his family (likert scale); perception of how important luck in life is, and whether people get what they deserve (both on scale 1 to 11); self-reported risk attitudes (scale 1 to 11). Robust standard errors in parentheses. ${ }^{* * *} \mathrm{p}<0.01,{ }^{* *} \mathrm{p}<0.05,{ }^{*} \mathrm{p}<0.1$. 
We now detail our main results by treatments using non-parametric analysis.

Result 1: When both donation amounts and efficiency are private information (T0), 18\% of subjects increase their giving when they receive good news, while bad news has no effect on giving.

In each treatment, about $25 \%$ of the information about charities' efficiency represents bad news for subjects. In treatment T0 we see virtually no variations from phase 1 to phase 2 in terms of donation amounts when news is bad $(\mathrm{p}=0.632)$ (only one subject reduces his giving for one of his charities). ${ }^{24}$ The same result holds when we consider reductions in donation between treatments: reductions after a bad news are significantly lower in T0 compared to treatments T1 and T2 pooled together $(\mathrm{p}=0.061)$. Differently, we see that when news is good, participants modify their donation behavior by increasing their contributions to better-than-expected charities $(\mathrm{p}=0.023)$. This suggests that that efficiency is complementary to the quantity donated. This result is driven by $18 \%$ of subjects who modify their giving, and the average percentage change in donations is $38 \%$. These represent the $13.6 \%$ of all subjects in T0. This suggests that about $18 \%$ of donors in T0 have preferences consistent with pure altruism, and that the substitution effect of a positive change in perceived quality is stronger than the income effect. This result also suggests that most donors in T0 do not modify their donations, a behavior compatible with warm-glow giving. The asymmetry between positive and negative news suggests that the same mechanism of imperfect updating found in other areas of decision making may be in place when it comes to evaluate negative information about charities people care about (see for instance Svenson (1981); Eil and Rao (2011); Sharot et al. (2011); Sharot et al. (2012); Mobius, Niederle, Niehaus and Rosenblat (2012)).

Result 2: When efficiency is private information but the final donation amount is disclosed to others (T1), 16\% of subjects increase their giving when they receive good news, and 25\% of subjects decrease their giving when they receive bad news.

In T1, when people respond to new information, good news is rewarded with increased average donations $(\mathrm{p}=0.006)$, while response to bad news is associated with average reductions in donation levels $(\mathrm{p}=0.027) .{ }^{25} 16 \%$ of the subjects who receive good news increase their donation, with average percentage increase of $21.5 \%$. These represent $12 \%$ of all subjects in T1. The negative variation after bad news is instead driven by $25 \%$ of the subjects, with an average percentage decrease of $7.6 \%$. These represent the $6 \%$ of all subjects in $\mathrm{T} 1$. Although in $\mathrm{T} 1$ the donation amount to the final charity is revealed to other participants,

\footnotetext{
${ }^{24}$ In treatment $\mathrm{T} 0$, the average donation in phase 1 before a bad news is $9.3 \mathrm{E} \$$, and $9.1 \mathrm{E} \$$ in phase 2 after bad news is received. In treatment $\mathrm{T} 1$ is $9.8 \mathrm{E} \$$ and $8 \mathrm{E} \$$ respectively; in treatment $\mathrm{T} 2,12.1 \mathrm{E} \$$ in phase 1 , and $11.4 \mathrm{E} \$$ in phase 2 .

${ }^{25}$ Average reduction in response to bad news is $2.16 \mathrm{E} \$$ (s.d. 3.14), and average increase in response to good news is $1.07 \mathrm{E} \$$ (s.d. 2.64).
} 
the signaling value of information about efficiency in $\mathrm{T} 0$ and $\mathrm{T} 1$ is the same. It is surprising thus to observe that making the donation amount public induces a minority of participants to vary their donation amounts in response to bad news. A possible explanation is that the visibility of the final donation amount raises the salience of information about efficiency, making subjects more sensitive to information that they would otherwise disregard. This is consistent with the notion that taking into account negative information has a psychological cost, which is avoided as far as the effort needed to ignore such information is low (see Benabou and Tirole 2002). ${ }^{26}$

Result 3: When efficiency is revealed to other participants, a significant fraction of subjects reduce their giving when they receive good news, and increase their giving when they receive bad news.

When the efficiency of the final charity is public information (T2), we observe two major differences with respect to T0 and T1. First, the percentage of subjects that change their donations between phases in response to new information is significantly higher in $\mathrm{T} 2 .{ }^{27}$ Second, while in $\mathrm{T} 0$ and $\mathrm{T} 1$ giving is always increasing in the quality of the news, in treatment T2 this relationship breaks down: 12 out of $33(36 \%)$ variations after good news is received are decreased donations, and 4 out of 14 (28.5\%) variations after bad news is received are increased donations. As shown earlier, our Tobit model indicates that in T2 for each one percentage point increase in real efficiency there is a $\mathrm{E} \$ 0.087$ drop $(\mathrm{p}=0.029)$ in donations in phase 2. To understand the reason for this difference, we divide subjects from T2 in two groups: in one group we place all subjects that have at least one decreased donation after good news (or one increased donation after a bad news). This represents the group of subjects displaying a behavior absent from T0 and T1. For simplicity we call these decisions "deviant" observations. In the second group, we place all "non-deviant" subjects from T2. ${ }^{28}$ Table 5 presents summary statistics of our main variables for the two groups from T2, and shows for each variable the results of Wilcoxon-Mann-Whitney tests.

\footnotetext{
${ }^{26}$ Alternatively, one may argue that individuals use donation amounts to indirectly signal that they do care about efficiency: suppose individuals hold correct priors about what would be the average contribution from a donor that cares about his charities; as high donations may signal that the subject chose a very efficient charity, a low donation may signal that the individual is responding to information that he believes is important for others. The latter interpretation has however some shortfalls: first, participants know that others do not observe their own initial decision; therefore, any public donation provides no information about whether the individual changed or not his previous decision (and in which direction). Moreover, making a small contribution represents a noisy signal: a small donation may either signal that the person is punishing a charity, or that the individual is simply greedy. The only explanation we can exclude is that bad news is used as an excuse not to give: that being the case in fact, we should observe the same behavior in treatment $\mathrm{T} 0$.

${ }^{27}$ The percentage of donations modified in phase 2 for T0, T1, and T2 are, respectively, $18.5 \%, 21 \%, 39 \%$ $(\mathrm{p}=0.001)$.

${ }^{28}$ Our analysis holds also if we categorize as deviant those subjects who have two deviant observations, instead of one.
} 
Table 5: Summary Statistics for T2's deviant and non-deviant observations

\begin{tabular}{|c|c|c|c|}
\hline$\overline{\text { Summary Statistics }}$ & Group 2 (non deviant) & Group 1 (deviant) & Z-stat (WMW Test) \\
\hline Donation Phase 1 & $\begin{array}{c}8.208 \\
(8.505)\end{array}$ & $\begin{array}{l}10.527 \\
(5.886)\end{array}$ & $-2.288^{* *}$ \\
\hline Donation Phase 2 & $\begin{array}{c}8.708 \\
(8.752)\end{array}$ & $\begin{array}{c}9.277 \\
(6.755)\end{array}$ & -0.946 \\
\hline Donation Phase 2 (Favorite) & $\begin{array}{c}9.869 \\
(9.299)\end{array}$ & $\begin{array}{c}12 \\
(7.469)\end{array}$ & -0.831 \\
\hline Donation Phase 2 (non-Favorites) & $\begin{array}{c}8.342 \\
(8.607)\end{array}$ & $\begin{array}{c}8.08 \\
(6.197)\end{array}$ & -0.518 \\
\hline Efficiency Guess & $\begin{array}{c}68.103 \\
(18.708)\end{array}$ & $\begin{array}{c}71.319 \\
(16.523)\end{array}$ & -0.880 \\
\hline Real Efficency & $\begin{array}{c}80.027 \\
(14.009)\end{array}$ & $\begin{array}{c}80.063 \\
(12.756)\end{array}$ & 0.222 \\
\hline News (Real Efficiency - Guess) & $\begin{array}{c}11.923 \\
(21.965)\end{array}$ & $\begin{array}{c}8.744 \\
(20.080)\end{array}$ & 0.779 \\
\hline News for Phase 1 favorite charity & $\begin{array}{c}6.352 \\
(28.062)\end{array}$ & $\begin{array}{c}5.800 \\
(11.146)\end{array}$ & 0.169 \\
\hline News for Phase 2 favorite charity & $\begin{array}{c}11.895 \\
(20.520)\end{array}$ & $\begin{array}{c}11.6 \\
(17.128)\end{array}$ & -0.534 \\
\hline N. Good News $(\min =0 ; \max =3)$ & $\begin{array}{c}2.437 \\
(0.792)\end{array}$ & $\begin{array}{c}2 \\
(1.014)\end{array}$ & $2.343^{* *}$ \\
\hline \% Choosing a Favorite in Phase 2 & $\begin{array}{l}23.9 \% \\
(0.429)\end{array}$ & $\begin{array}{c}30.5 \% \\
(0.467)\end{array}$ & -0.769 \\
\hline
\end{tabular}

Note: s.d. in parenthesis. ${ }^{* * *} p<0.01,{ }^{* *} p<0.05,{ }^{*} p<0.1$

Table 5 shows that the two groups receive on average the same composition of good and bad news $(\mathrm{p}=0.179) .{ }^{29}$ Since most of the "deviant" observations are observed when good news is received, this suggests that "deviant" subjects are not just receiving all good news and rewarding the best, causing otherwise efficient charities to experience decreased donations. On the contrary, "deviant" subjects receive on average slightly less good news than "non deviant" subjects (respectively 2 and $2.43, \mathrm{p}=0.019$ ). We can also reject the hypothesis that subjects hold different beliefs about their charities across the two groups $(\mathrm{p}=0.376)$. Figure 3 shows the distribution of good and bad news for the two groups from treatment T2.

\footnotetext{
${ }^{29}$ The same conclusion can be drawn using a two-groups proportion test $(\mathrm{p}=0.518)$.
} 
Figure 3: Distribution of news for Group 2 (non-deviant) and Group 1 (deviant) subjects in $\mathrm{T} 2$

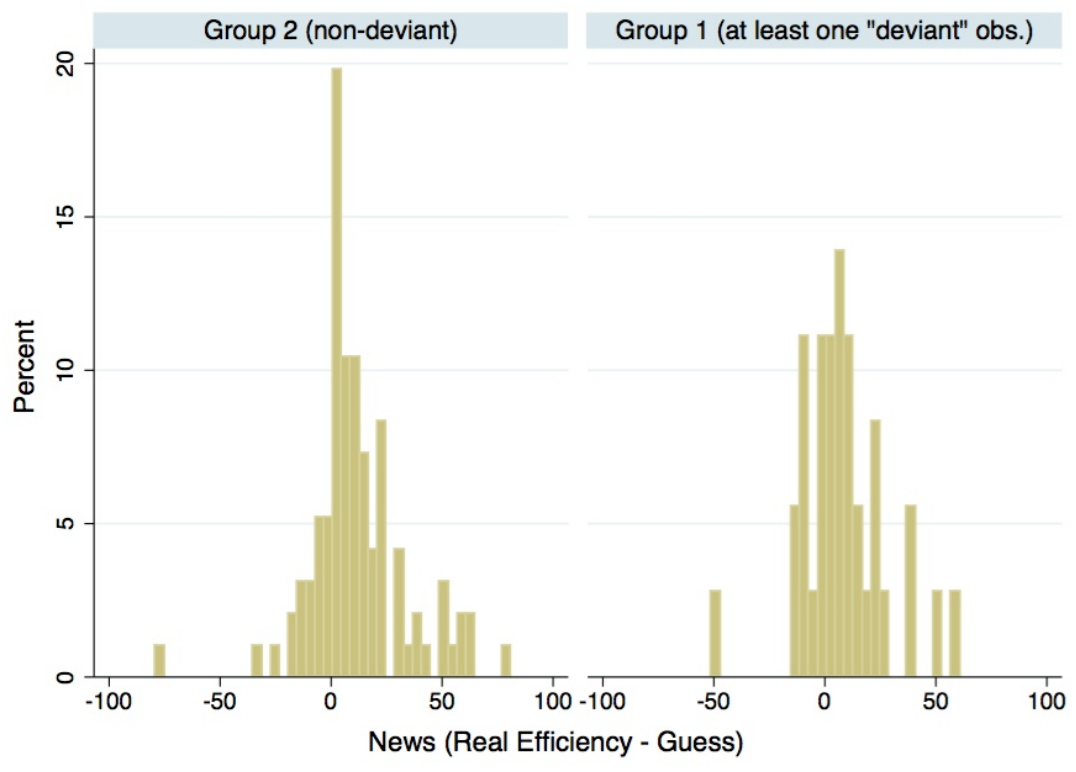

Information and beliefs are not statistically different across the two groups. We compare thus donation decisions and choices of a favorite charity. First, we find that deviant subjects donate significantly more in phase 1 compared to non-deviant subjects $(p=0.024)$; the difference between the two groups however disappears in phase 2 donations $(p=0.341)$. For deviant subjects, average donations in phase 2 are not different from phase $1(\mathrm{p}=0.319)$. For non-deviant subjects instead, as it is for treatments $\mathrm{T} 0$ and $\mathrm{T} 1$, average contributions increase across phases $(\mathrm{p}=0.015)$, a r. Second, deviant subjects switch their favorite charity more than non-deviant subjects do $(\mathrm{p}=0.000)$, and they always switch toward of a more efficient charity. We find no evidence that deviant subjects are hedging between nonfavorites and the favorite charity. We find that charities not indicated as favorites in phase 2 face a significant reduction in giving across phases $(p=0.002)$. However, final donations from deviant subjects to their favorite charities are not statistically different from donations made in phase $1(\mathrm{p}=0.119)$.

Together, these results support the hypothesis that deviant subjects are relatively more motivated by social image. The argument is simple: in phase 1, the only way an imagemotivated donor has to signal his pro-sociality is to donate a large portion of his endowment. However, in phase 2, a image conscience donor would discover that there are two ways to earn the esteem of others: donate a large portion of his endowment, or donate a somewhat smaller amount to an efficient charity. In other words, image-motivated donors may substitute donations for efficiency, increasing both their take-home earnings and social 
esteem. When news is good thus, the relative cost of looking pro-social decreases across phases. Our results thus show that indeed social conscience donors care about the image consequence of charitable output, and that the availability of positive information reduces the cost of looking pro-social, generating an income effect stronger than the substitution effect. An alternative interpretation is that image-motivated donors target a specific charitable output amount to maximize utility, and when efficiency is better than expected, they maintain the size of the target charitable output by decreasing the donation amount (see Camerer et al. 1997).

\section{Conclusion}

We set out to investigate the effect information about charities' efficiency and its public visibility have on the intensive margins of charitable giving. Using a laboratory experiment with treatments that progressively increase the visibility of donation amounts and charities' efficiency, we assess the relative importance of two forces: on the one hand greater perceived quality of charities may increase nominal giving, since donors perceive that it is cheaper to generate charitable output. On the other hand an increase in perceived quality may crowdout giving since donors may believe they can provide a higher or equal level of charitable output with lower nominal donations. We hypothesize that such income and substitution effects affect decisions of donors who give out of pure altruism, and of social conscience donors whenever information about charities' qualities can affect their social image returns. Our data show no evidence of an income effect when information is received privately. On the contrary, we find that between 16 and $18 \%$ of donors increase their donations when discovering that their charities are better-than-expected. We also find that individuals tend to disregard bad news about their own charities when giving happens under full anonymity. This result also implies that under full anonymity of giving, a large portion of donors do not respond to information about charities' efficiency, a behavior that would be expected if donors only care about the act of giving itself (warm-glow). Differently, we find that when information has a social signaling value, $34 \%$ of donors who change their decisions do so by reducing their donations after receiving good news about their charities' efficiency, and increasing donations after receiving bad news. We show that this result is driven by individuals who are relatively more motivated by social-image, who strategically reduce their nominal giving whenever a new and costless positive social signal can be conveyed to others. Our experiment sheds light on effect information has on the intensive margins of the market for giving (e.g. existing donors). One limitation of our study is that the positive or negative valence of information depends on participants' subjective priors. Future work may look at how donors who are already objectively informed about a given measure of effectiveness respond to an exogenous change of such measure. Future work may also take advantage of our approach to study the effect of information on the extensive margins of giving (e.g. new donors). Our results suggest that public information changes the relative 
cost of looking pro-social for image motivated donors. While we find that this effect reduces giving from existing donors, it may instead incentivize non-donors to start giving because the presence of public information about charities' quality may reduce the cost of looking pro-social.

\section{References}

[1] George A Akerlof and Rachel E Kranton. Economics and identity. The Quarterly Journal of Economics, 115(3):715-753, 2000.

[2] James Andreoni. Privately provided public goods in a large economy: the limits of altruism. Journal of public Economics, 35(1):57-73, 1988.

[3] James Andreoni. Why free ride?: Strategies and learning in public goods experiments. Journal of Public Economics, 37(3):291-304, 1988.

[4] James Andreoni. Giving with impure altruism: Applications to charity and ricardian equivalence. The Journal of Political Economy, 97(6):1447-1458, 1989.

[5] James Andreoni. Impure altruism and donations to public goods: a theory of warmglow giving. The Economic Journal, 100(401):464-477, 1990.

[6] James Andreoni and John Miller. Giving according to garp: An experimental test of the consistency of preferences for altruism. Econometrica, 70(2):737-753, 2003.

[7] James Andreoni and A Abigail Payne. Is crowding out due entirely to fundraising? evidence from a panel of charities. Journal of Public Economics, 95(5):334-343, 2011.

[8] James Andreoni and Ragan Petrie. Public goods experiments without confidentiality: a glimpse into fund-raising. Journal of Public Economics, 88(7):1605-1623, 2004.

[9] James Andreoni, Justin M Rao, and Hannah Trachtman. Avoiding the ask: A field experiment on altruism, empathy, and charitable giving. Technical report, National Bureau of Economic Research, 2011.

[10] Dan Ariely, Anat Bracha, and Stephan Meier. Doing good or doing well? image motivation and monetary incentives in behaving prosocially. American Economic Review, 99(1):544-555, 2009.

[11] Kenneth Joseph Arrow and Frank Horace Hahn. General competitive analysis. HoldenDay San Francisco, 1971.

[12] Gary S Becker. A theory of social interactions. Journal of Political Economy, 82(6):1063-93, 1974. 
[13] Roland Bénabou and Jean Tirole. Self-confidence and personal motivation. The Quarterly Journal of Economics, 117(3):871-915, 2002.

[14] Roland Bénabou and Jean Tirole. Incentives and prosocial behavior. The American Economic Review, 96(5):1652-1678, 2006.

[15] Theodore Bergstrom, Lawrence Blume, and Hal Varian. On the private provision of public goods. Journal of public economics, 29(1):25-49, 1986.

[16] Anat Bracha, Ori Heffetz, and Lise Vesterlund. Charitable giving: The effects of exogenous and endogenous status. Technical report, University of Pittsburgh Working Paper, 2009.

[17] Anat Bracha, Michael Menietti, and Lise Vesterlund. Seeds to succeed?: Sequential giving to public projects. Journal of Public Economics, 95(5):416-427, 2011.

[18] Alexander L Brown, Jonathan Meer, and J Forrest Williams. Social distance and quality ratings in charity choice. Journal of Behavioral and Experimental Economics, 2016.

[19] Colin Camerer, Linda Babcock, George Loewenstein, and Richard Thaler. Labor supply of new york city cabdrivers: One day at a time. The Quarterly Journal of Economics, 112(2):407-441, 1997.

[20] Raj Chetty. A new method of estimating risk aversion. The American Economic Review, 96(5):1821-1834, 2006.

[21] Nadine Chlaß, Lata Gangadharan, and Kristy Jones. Charitable giving and intermediation. Jena Economic Research Papers, 2015:021, 2015.

[22] Stefano DellaVigna, John A List, and Ulrike Malmendier. Testing for altruism and social pressure in charitable giving. The quarterly journal of economics, 127(1):1-56, 2012 .

[23] Catherine Eckel, Angela De Oliveira, and Philip Grossman. Is more information always better? an experimental study of charitable giving and hurricane katrina. Southern Economic Journal, 74(2):388-411, 2007.

[24] Catherine Eckel and Philip Grossman. Altruism in anonymous dictator games. Games and economic behavior, 16(2):181-191, 1996.

[25] David Eil and Justin M Rao. The good news-bad news effect: Asymmetric processing of objective information about yourself. American Economic Journal: Microeconomics, 3(2):114-138, 2011. 
[26] Urs Fischbacher, Simon Gächter, and Ernst Fehr. Are people conditionally cooperative? evidence from a public goods experiment. Economics Letters, 71(3):397-404, 2001.

[27] Christina M Fong. Evidence from an experiment on charity to welfare recipients: Reciprocity, altruism and the empathic responsiveness hypothesis. The Economic Journal, 117(522):1008-1024, 2007.

[28] Christina M Fong and Felix Oberholzer-Gee. Truth in giving: Experimental evidence on the welfare effects of informed giving to the poor. Journal of Public Economics, 95(5):436-444, 2011.

[29] Uri Gneezy, Elizabeth A Keenan, and Ayelet Gneezy. Avoiding overhead aversion in charity. Science, 346(6209):632-635, 2014.

[30] Zachary Grossman. Self-signaling versus social-signaling in giving. working paper, 2010.

[31] William T Harbaugh. The prestige motive for making charitable transfers. The American Economic Review, 88(2):277-282, 1998.

[32] William T Harbaugh. What do donations buy?: A model of philanthropy based on prestige and warm glow. Journal of Public Economics, 67(2):269-284, 1998.

[33] William T Harbaugh, Ulrich Mayr, and Daniel R Burghart. Neural responses to taxation and voluntary giving reveal motives for charitable donations. Science, 316(5831):1622-1625, 2007.

[34] Heinz Holländer. A social exchange approach to voluntary cooperation. The American Economic Review, 80(5):1157-1167, 1990.

[35] Daniel Jones and Sera Linardi. Wallflowers: Experimental evidence of an aversion to standing out. Management Science, 60(7):1757-1771, 2014.

[36] Dean Karlan and John A List. Does price matter in charitable giving? evidence from a large-scale natural field experiment. The American Economic Review, 97(5):1774$1793,2007$.

[37] Dean Karlan and Daniel H Wood. The effect of effectiveness: Donor response to aid effectiveness in a direct mail fundraising experiment. Journal of Behavioral and Experimental Economics, 2016.

[38] John A List and David Lucking-Reiley. The effects of seed money and refunds on charitable giving: Experimental evidence from a university capital campaign. Journal of Political Economy, 110(1):215-233, 2002. 
[39] Jonathan Meer. Are overhead costs a good guide for charitable giving? IZA World of Labor, pages 329-329, 2017.

[40] Markus M. Mobius, Muriel Niederle, Paul Niehaus, and Tanya S. Rosenblat. Managing self-confidence: Theory and experimental evidence. Working Paper 17014, National Bureau of Economic Research, May 2011.

[41] Alvaro J Name-Correa and Huseyin Yildirim. giving in to social pressure. Games and Economic Behavior, 99:99-116, 2016.

[42] Douglass North. Growth and structural change. 1981.

[43] Clair Null. Warm glow, information, and inefficient charitable giving. Journal of Public Economics, 95(5):455-465, 2011.

[44] Carlo Perroni, Ganna Pogrebna, Sarah Sandford, and Kimberley A Scharf. Are donors afraid of charities' core costs? scale economies in non-profit provision. 2014.

[45] Jan Potters, Martin Sefton, and Lise Vesterlund. Leading-by-example and signaling in voluntary contribution games: an experimental study. Economic Theory, 33(1):169$182,2007$.

[46] Mari Rege and Kjetil Telle. The impact of social approval and framing on cooperation in public good situations. Journal of Public Economics, 88(7):1625-1644, 2004.

[47] David C Ribar and Mark O Wilhelm. Altruistic and joy-of-giving motivations in charitable behavior. Journal of Political Economy, 110(2):425-457, 2002.

[48] Jen Shang and Rachel Croson. A field experiment in charitable contribution: The impact of social information on the voluntary provision of public goods. The Economic Journal, 119(540):1422-1439, 2009.

[49] Tali Sharot, Ryota Kanai, David Marston, Christoph W Korn, Geraint Rees, and Raymond J Dolan. Selectively altering belief formation in the human brain. Proceedings of the National Academy of Sciences, 109(42):17058-17062, 2012.

[50] Tali Sharot, Christoph W Korn, and Raymond J Dolan. How unrealistic optimism is maintained in the face of reality. Nature neuroscience, 14(11):1475-1479, 2011.

[51] Robert Sugden. Reciprocity: the supply of public goods through voluntary contributions. The Economic Journal, 94(376):772-787, 1984.

[52] Ola Svenson. Are we all less risky and more skillful than our fellow drivers? Acta Psychologica, 47(2):143-148, 1981.

[53] Lise Vesterlund. The informational value of sequential fundraising. Journal of Public Economics, 87(3):627-657, 2003. 


\section{Appendix A}

Table 6: Number of charities selected in each sub-sector, by treatment

\begin{tabular}{|c|c|c|c|}
\hline Treatment & T0 & T1 & $\mathrm{T} 2$ \\
\hline Charities' sub-sectors & n. $(\%)$ & n. $(\%)$ & n. $(\%)$ \\
\hline Advocacy and Civil Rights & $4(4.94 \%)$ & $1(1.19 \%)$ & $6(4.55 \%)$ \\
\hline Animal Rights, Welfare, and Services & $3(3.7 \%)$ & $8(9.52 \%)$ & $7(5.3 \%)$ \\
\hline Children's and Family Services & 0 & $4(4.76 \%)$ & $1(0.76 \%)$ \\
\hline Community Foundations & $1(1.23 \%)$ & 0 & 0 \\
\hline Community and Housing Development & 0 & $1(1.19 \%)$ & $5(3.79 \%)$ \\
\hline Development and Relief Services & $7(8.64 \%)$ & $8(9.52 \%)$ & $14(10.61 \%)$ \\
\hline Diseases, Disorders, and Disciplines & $10(12.35 \%)$ & $8(9.52 \%)$ & $19(14.39 \%)$ \\
\hline Environmental Protection and Conservation & $5(6.17 \%)$ & $3(3.57 \%)$ & $3(2.27 \%)$ \\
\hline Food Banks, Food Pantries, and Food Distribution & 0 & $1(1.19 \%)$ & $2(1.52 \%)$ \\
\hline Fundraising Organizations & $4(4.94 \%)$ & $7(8.33 \%)$ & $6(4.55 \%)$ \\
\hline Homeless Services & $1(1.23 \%)$ & 0 & $1(0.76 \%)$ \\
\hline Humanitarian Relief Supplies & $2(2.47 \%)$ & $3(3.57 \%)$ & $3(2.27 \%)$ \\
\hline International Peace, Security, and Affairs & $3(3.7 \%)$ & 0 & $4(3.03 \%)$ \\
\hline Libraries, Historical Societies and Landmark Preservation & $11.23 \%)$ & 0 & $1(0.76 \%)$ \\
\hline Medical Research & $3(3.7 \%)$ & $7(8.33 \%)$ & $5(3.79 \%)$ \\
\hline Multipurpose Human Service Organizations & $67.41 \%)$ & $1(1.19 \%)$ & $9(6.82 \%)$ \\
\hline Museums & $4(4.94 \%)$ & $3(3.57 \%)$ & $3(2.27 \%)$ \\
\hline Other Education Programs and Services & $6(7.41 \%)$ & $5(5.95 \%)$ & $10(7.58 \%)$ \\
\hline Patient and Family Support & $5(6.17 \%)$ & $1(1.19 \%)$ & $6(4.55 \%)$ \\
\hline Performing Arts & 0 & $1(1.19 \%)$ & $1(0.76 \%)$ \\
\hline Public Broadcasting and Media & $22.47 \%)$ & 0 & 0 \\
\hline Religious Activities & $2(2.47 \%)$ & $6(7.14 \%)$ & $2(1.52 \%)$ \\
\hline Religious Media and Broadcasting & $1(1.23 \%)$ & 0 & $1(0.76 \%)$ \\
\hline Research and Public Policy Institutions & 0 & $1(1.19 \%)$ & $1(0.76 \%)$ \\
\hline Single Country Support Organizations & $1(1.23 \%)$ & $4(4.76 \%)$ & $1(0.76 \%)$ \\
\hline Social Services & $4(4.94 \%)$ & $6(7.14 \%)$ & $7(5.3 \%)$ \\
\hline Treatment and Prevention Services & $1(1.23 \%)$ & 0 & $4(3.03 \%)$ \\
\hline Wildlife Conservation & $3(3.7 \%)$ & $1(1.19 \%)$ & $2(1.52 \%)$ \\
\hline Youth Development, Shelter, and Crisis Services & $1(1.23 \%)$ & $3(3.57 \%)$ & $6(4.55 \%)$ \\
\hline Zoos and Aquariums & $1(1.23 \%)$ & $1(1.19 \%)$ & $2(1.52 \%)$ \\
\hline Total & 81 & 84 & 132 \\
\hline
\end{tabular}




\begin{tabular}{|c|c|c|c|c|}
\hline Treatment & T0 & T1 & $\mathrm{T} 2$ & Total \\
\hline Charity's Name & $\mathrm{n}$. & n. & $\mathrm{n}$. & n. \\
\hline "I Have a Dream" Foundation & 2 & 3 & 4 & 9 \\
\hline 10,000 Degrees & 2 & 0 & 2 & 4 \\
\hline 100 Club of Arizona & 0 & 0 & 1 & 1 \\
\hline 1000 Friends of Florida & 2 & 0 & 1 & 3 \\
\hline 4 Paws for Ability & 0 & 1 & 1 & 2 \\
\hline A Better Chance & 1 & 0 & 1 & 2 \\
\hline A Gift for Teaching & 0 & 0 & 2 & 2 \\
\hline A Kid Again & 0 & 0 & 2 & 2 \\
\hline AAA Foundation for Traffic Safety & 0 & 0 & 1 & 1 \\
\hline AARP Foundation & 1 & 0 & 0 & 1 \\
\hline AAUW - American Association of University Women & 0 & 0 & 1 & 1 \\
\hline ACCESS College Foundation & 0 & 1 & 0 & 1 \\
\hline ACE Scholarships & 0 & 0 & 2 & 2 \\
\hline AIDS Emergency Fund & 0 & 1 & 1 & 2 \\
\hline AIDS Research Alliance & 1 & 0 & 0 & 1 \\
\hline ALS Therapy Development Institute & 0 & 0 & 1 & 1 \\
\hline ALSAC - St. Jude Children's Research Hospital & 1 & 2 & 4 & 7 \\
\hline Abused Deaf Women's Advocacy Services & 0 & 0 & 1 & 1 \\
\hline Action Against Hunger - ACF-USA & 0 & 0 & 1 & 1 \\
\hline Action for Healthy Kids & 0 & 0 & 1 & 1 \\
\hline Adopt A Pet.com & 0 & 1 & 1 & 2 \\
\hline Adventure Unlimited & 0 & 0 & 1 & 1 \\
\hline African Enterprise & 0 & 1 & 0 & 1 \\
\hline African Wildlife Foundation & 1 & 0 & 1 & 2 \\
\hline Africare & 0 & 0 & 1 & 1 \\
\hline After-School All-Stars & 0 & 0 & 1 & 1 \\
\hline Aid For Friends & 0 & 1 & 0 & 1 \\
\hline Aid for Starving Children & 1 & 2 & 2 & 5 \\
\hline Akron-Canton Regional Foodbank & 0 & 1 & 0 & 1 \\
\hline Alex's Lemonade Stand Foundation & 1 & 0 & 0 & 1 \\
\hline All Children's Hospital Foundation & 2 & 0 & 0 & 2 \\
\hline Aloha United Way & 0 & 0 & 1 & 1 \\
\hline Amazon Conservation Association & 1 & 0 & 0 & 1 \\
\hline American Breast Cancer Foundation & 2 & 0 & 1 & 3 \\
\hline American Cancer Society & 1 & 1 & 3 & 5 \\
\hline American Diabetes Association & 0 & 1 & 2 & 3 \\
\hline American Foundation For Children With AIDS & 1 & 0 & 0 & 1 \\
\hline American Foundation for Disabled Children & 1 & 0 & 0 & 1 \\
\hline
\end{tabular}




\begin{tabular}{|c|c|c|c|}
\hline American Friends of Nishmat & 0 & 0 & 1 \\
\hline American Heart Association & 2 & 2 & 0 \\
\hline American Institute for Cancer Research & 0 & 1 & 0 \\
\hline American Lung Association of the Mid-Atlantic & 1 & 0 & 1 \\
\hline American Red Cross & 4 & 1 & 5 \\
\hline American Society for the Prevention of Cruelty to Animals & 0 & 2 & 0 \\
\hline American Society for the Protection of Nature in Israel & 0 & 1 & 0 \\
\hline American Youth Foundation & 0 & 1 & 0 \\
\hline Amnesty International USA & 0 & 0 & 1 \\
\hline Animal Friends & 0 & 0 & 1 \\
\hline Animal Humane Society & 2 & 2 & 0 \\
\hline Animal Rescue & 0 & 1 & 1 \\
\hline Animal Rescue League of Iowa & 0 & 1 & 0 \\
\hline Animal Welfare Society & 0 & 0 & 1 \\
\hline Aquarium of the Pacific & 1 & 0 & 0 \\
\hline Arlington Food Assistance Center & 1 & 0 & 0 \\
\hline Army Emergency Relief & 0 & 0 & 1 \\
\hline Arthur Ashe Youth Tennis and Education & 1 & 0 & 0 \\
\hline Autism Research Institute & 0 & 1 & 0 \\
\hline Autism Speaks & 0 & 0 & 3 \\
\hline Big Brothers Big Sisters of America & 0 & 1 & 0 \\
\hline Billy Graham Evangelistic Association & 0 & 0 & 1 \\
\hline Books For Africa & 0 & 1 & 0 \\
\hline Boy Scouts of America, National Capital Area Council & 0 & 1 & 0 \\
\hline Breast Cancer Research Foundation & 2 & 1 & 0 \\
\hline COSI Columbus & 0 & 0 & 1 \\
\hline CURE Childhood Cancer & 0 & 0 & 1 \\
\hline California Police Activities League & 0 & 0 & 1 \\
\hline Cancer Research Institute & 0 & 4 & 1 \\
\hline Catholic Charities Health and Human Services & 0 & 1 & 0 \\
\hline Catholic Charities USA & 0 & 1 & 0 \\
\hline Catholic Schools Foundation & 0 & 1 & 0 \\
\hline Central Virginia Foodbank & 0 & 0 & 1 \\
\hline Chesapeake Bay Foundation & 1 & 1 & 0 \\
\hline Chesapeake Bay Maritime Museum & 1 & 0 & 0 \\
\hline Chesapeake Bay Trust & 1 & 0 & 0 \\
\hline Childcare Worldwide & 0 & 0 & 1 \\
\hline Children Cancer Research Fund & 0 & 1 & 0 \\
\hline Children in Crisis & 0 & 2 & 0 \\
\hline Children's Hospital Foundation & 0 & 0 & 2 \\
\hline Children's Hunger Fund & 0 & 1 & 1 \\
\hline
\end{tabular}


Children's Miracle Network

Children's Organ Transplant Association

Children's Rights

Children's Scholarship Fund

China Care Foundation

Citymeals-on-Wheels

Council for Secular Humanism

Cystic Fibrosis Research, Inc.

D.A.R.E. America

D.C. Bar Pro Bono Program

Dance/USA

Diabetes Research Institute Foundation

Doctors Without Borders, USA

Dogs for the Deaf

Engineering Ministries International

FDNY Foundation

Feed My Starving Children

Food For The Poor

Food for the Hungry

Foodbank of Southeastern Virginia

Friends of the National Zoo

Fund for Armenian Relief

Futures Without Violence

Girl Scouts of the USA

Global Fund for Children

Guide Dogs for the Blind

HOPE International

Habitat for Humanity - New York City

Habitat for Humanity of Northern Virginia

Hawaii Food Bank

Heart for Africa

Hillel: The Foundation for Jewish Campus Life

Houston Zoo

Human Rights Campaign Foundation

Humane Society of Fairfax County

India Development and Relief Fund

Institute of International Education

InterVarsity Christian Fellowship/USA

International Children's Care

International Orthodox Christian Charities

Invisible Children

$\begin{array}{llll}0 & 1 & 0 & 1 \\ 0 & 0 & 1 & 1 \\ 0 & 0 & 1 & 1 \\ 1 & 0 & 0 & 1 \\ 0 & 1 & 0 & 1 \\ 0 & 1 & 0 & 1 \\ 0 & 0 & 1 & 1 \\ 1 & 0 & 0 & 1 \\ 0 & 0 & 2 & 2 \\ 1 & 0 & 0 & 1 \\ 0 & 1 & 0 & 1 \\ 0 & 1 & 0 & 1 \\ 2 & 0 & 0 & 2 \\ 0 & 0 & 1 & 1 \\ 0 & 0 & 1 & 1 \\ 0 & 0 & 1 & 1 \\ 0 & 0 & 1 & 1 \\ 0 & 0 & 1 & 1 \\ 1 & 0 & 0 & 1 \\ 0 & 0 & 1 & 1 \\ 0 & 1 & 1 & 2 \\ 0 & 0 & 1 & 1 \\ 0 & 0 & 1 & 1 \\ 0 & 0 & 1 & 1 \\ 0 & 0 & 1 & 1 \\ 0 & 1 & 0 & 1 \\ 0 & 1 & 0 & 1 \\ 0 & 0 & 1 & 1 \\ 0 & 1 & 2 & 3 \\ 1 & 0 & 0 & 1 \\ 1 & 0 & 1 & 2 \\ 1 & 0 & 0 & 1 \\ 0 & 0 & 1 & 1 \\ 0 & 0 & 1 & 1 \\ 0 & 0 & 2 & 2 \\ 0 & 1 & 0 & 1 \\ 0 & 0 & 1 & 1 \\ 0 & 1 & 0 & 1 \\ 1 & 0 & 0 & 1 \\ 0 & 1 & 0 & 1 \\ 0 & 1 & 0 & 1\end{array}$


Islamic Relief USA

Juvenile Diabetes Research Foundation International

Kiddo

Kids in Crisis

Law Enforcement Education Program

Law Enforcement Legal Defense Fund

Link Media and Link TV

Love146

Lung Cancer Alliance

Magic Johnson Foundation

Make-A-Wish Foundation of America

Make-A-Wish Foundation of Greater Virginia

Make-A-Wish Foundation of Metro New York

Make-A-Wish International

Mary's Center for Maternal and Child Care

Mission Without Borders - USA

Mothers Against Drunk Driving

Multiple Sclerosis Association of America

Muscular Dystrophy Association

Muslim American Society

NPR

NRA Special Contribution Fund, Whittington Center

Naismith Memorial Basketball Hall of Fame

National Alliance to End Homelessness

National Association for the Advancement of Colored People

National Council on US-Arab Relations

National Foundation for Advancement in the Arts

National Foundation for Infectious Diseases

National Jewish Health

National Law Enforcement Officers Memorial Fund

Neurosciences Research Foundation

North American Conference on Ethiopian Jewry

Organic Farming Research Foundation

Palestine Children's Relief Fund

Pennsylvania SPCA

Planned Parenthood Federation of America

Planned Parenthood of Metropolitan Washington, DC

Pratham USA

Prevent Child Abuse America

RBC Ministries

Rainforest Alliance

$\begin{array}{llll}2 & 2 & 2 & 6 \\ 1 & 0 & 0 & 1 \\ 0 & 0 & 1 & 1 \\ 0 & 0 & 1 & 1 \\ 1 & 0 & 1 & 2 \\ 0 & 0 & 1 & 1 \\ 0 & 0 & 1 & 1 \\ 1 & 0 & 0 & 1 \\ 0 & 0 & 1 & 1 \\ 0 & 0 & 1 & 1 \\ 3 & 1 & 2 & 6 \\ 1 & 0 & 1 & 2 \\ 1 & 0 & 0 & 1 \\ 0 & 0 & 1 & 1 \\ 0 & 1 & 0 & 1 \\ 0 & 0 & 1 & 1 \\ 0 & 0 & 1 & 1 \\ 0 & 1 & 0 & 1 \\ 0 & 0 & 2 & 2 \\ 1 & 1 & 1 & 3 \\ 2 & 0 & 0 & 2 \\ 1 & 0 & 0 & 1 \\ 1 & 0 & 0 & 1 \\ 0 & 0 & 1 & 1 \\ 0 & 0 & 1 & 1 \\ 1 & 0 & 0 & 1 \\ 0 & 1 & 0 & 1 \\ 0 & 1 & 0 & 1 \\ 0 & 0 & 1 & 1 \\ 1 & 0 & 1 & 2 \\ 0 & 0 & 1 & 1 \\ 0 & 0 & 1 & 1 \\ 0 & 1 & 0 & 1 \\ 0 & 1 & 0 & 1 \\ 1 & 0 & 0 & 1 \\ 1 & 0 & 0 & 1 \\ 0 & 0 & 1 & 1 \\ 1 & 0 & 0 & 1 \\ 0 & 1 & 0 & 1 \\ 1 & 0 & 0 & 1 \\ 0 & 0 & 1 & 1\end{array}$


Ronald McDonald House Charities

Samaritan's Purse

Save the Children

Second Amendment Foundation

Shelter for Abused Women \& Children

Shelter for the Homeless

Smithsonian Institution

South Florida Wildlife Center

Special Olympics Virginia

Stop Hunger Now

Susan G. Komen for the Cure

Teach For America

The Leukemia \& Lymphoma Society

The National Italian American Foundation

The Nature Conservancy

USO

United States Fund for UNICEF

United States Golf Association

Uniting Against Lung Cancer

Virginia Beach SPCA

Warm Blankets Orphan Care International

Washington Animal Rescue League

Washington National Opera

Water.org

Women Thrive Worldwide

World Emergency Relief

World Wildlife Fund

Wounded Warrior Project

YMCA of Greater Grand Rapids

Young Life

charity: water

$\begin{array}{llll}1 & 1 & 0 & 2\end{array}$

$\begin{array}{llll}1 & 0 & 0 & 1\end{array}$

$\begin{array}{llll}0 & 2 & 0 & 2\end{array}$

$\begin{array}{llll}0 & 1 & 0 & 1\end{array}$

$\begin{array}{llll}0 & 1 & 0 & 1\end{array}$

$\begin{array}{llll}1 & 0 & 0 & 1\end{array}$

$\begin{array}{llll}2 & 1 & 0 & 3\end{array}$

$\begin{array}{llll}0 & 1 & 0 & 1\end{array}$

$\begin{array}{llll}0 & 0 & 1 & 1\end{array}$

$\begin{array}{llll}0 & 0 & 1 & 1\end{array}$

$\begin{array}{llll}1 & 0 & 1 & 2\end{array}$

$\begin{array}{llll}0 & 0 & 1 & 1\end{array}$

$\begin{array}{llll}0 & 0 & 1 & 1\end{array}$

$\begin{array}{llll}1 & 0 & 0 & 1\end{array}$

$\begin{array}{llll}0 & 1 & 0 & 1\end{array}$

$\begin{array}{llll}0 & 0 & 1 & 1\end{array}$

$\begin{array}{llll}1 & 0 & 0 & 1\end{array}$

$\begin{array}{llll}1 & 0 & 0 & 1\end{array}$

$\begin{array}{llll}0 & 0 & 1 & 1\end{array}$

$\begin{array}{llll}0 & 1 & 0 & 1\end{array}$

$\begin{array}{llll}0 & 1 & 0 & 1\end{array}$

$\begin{array}{llll}0 & 0 & 1 & 1\end{array}$

$\begin{array}{llll}0 & 0 & 1 & 1\end{array}$

$\begin{array}{llll}0 & 0 & 1 & 1\end{array}$

\begin{tabular}{lccccc} 
endPoverty.org & 0 & 1 & 1 & 2 \\
\hline Total & 81 & 84 & 132 & 297 \\
\hline
\end{tabular}

Table 7: List of charities selected by treatment 


\section{Appendix B}

In this section we derive conditions for an increase or decrease of individual giving in response to an increase in quality using the implicit function theorem. For simplicity we assume that donors have homogeneous preferences and we ignore pure altruists' preferences over $G_{-i}$ (the results do not qualitatively change). A donor solves the following simple maximization problem:

$$
\begin{array}{r}
\max U_{i}=\nu(c)+u\left(q \cdot g_{i}\right) \\
\text { s.t. } M=c+g
\end{array}
$$

We assume that both $\nu$ and $u$ are strictly increasing and concave functions. Taking the first order conditions with respect to $g_{i}$ we obtain:

$$
\frac{\partial U}{\partial g_{i}}=-\nu^{\prime}(m-g)+q u^{\prime}\left(q \cdot g_{i}\right)=0
$$

If we implicitly differentiate the latter with respect to $q$ we obtain:

$$
+\nu^{\prime \prime}(m-g) \cdot \frac{\partial g_{i}}{\partial q}+u^{\prime}(q \cdot g)+q \cdot u^{\prime \prime}(q \cdot g) \cdot\left[g+q \cdot \frac{\partial g_{i}}{\partial q}\right]=0
$$

If we rearrange equation 7 we obtain:

$$
\frac{\partial g_{i}}{\partial q}=\frac{-u^{\prime}(q \cdot g)-q \cdot u^{\prime \prime}(q \cdot g) \cdot g}{\nu^{\prime \prime}(m-g)+q \cdot u^{\prime \prime}(q \cdot g) \cdot q}
$$

The denominator of equation 8 is always negative. Therefore giving will increase in response to increases in $q\left(\frac{\partial g_{i}}{\partial q}>0\right)$ if $-u^{\prime}(q \cdot g)-q \cdot u^{\prime \prime}(q \cdot g) \cdot g<0$. Giving will instead decrease in response to an increase in $q$ if $-u^{\prime}(q \cdot g)-q \cdot u^{\prime \prime}(q \cdot g) \cdot g>0$. 